Еселханова Гульжайна Абдыгасеновна

к.б.н., и.о заместителя Генерального директора по научной работе РГКП «Республиканский научно-исследовательский институт по охране труда Министерства труда и социальной защиты населения Республики Казахстан», г. Астана E-mail: nauka@rniiot.kz ORCID ID: 0000-0002-9508-300X

\title{
АДАПТАЦИОННЫЙ ПОТЕНЦИАЛ ОРГАНИЗМА РАБОТНИКОВ СТРОИТЕЛЬНОЙ ОТРАСЛИ
}

Eselkhanova Gulzhayna Abdygassenovna Ph.D., and. about the Deputy General director of scientific work Republican State Enterprise "Republican ResearchInstitute for Labor ProtectionMinistry of Labor and Socialprotection of the populationRepublic of Kazakhstan", Astana E-mail: nauka@rniiot.kz ORCID ID: 0000-0002-9508-300X

\section{ADAPTATION POTENTIAL OF THE ORGANISM OF EMPLOYEES OF THE CONSTRUCTION INDUSTRY}

Annotation. The article is devoted to the actual problem related to the professional activity, and the assessment of risks to the health of workers as a necessary element of the effective functioning of the labor protection management system in the enterprise in the light of modern requirements for it. An assessment of the functional state of the body of construction workers is given, recommendations aimed at managing risks in the field of labor protection are developed, ways of applying the results of the study to managing risks of the working environment and the work process are proposed.

Key words: functional system of workers, risk, health of workers, enterprise, labor protection management system.

Аннотация. Статья посвящена актуальной проблеме связанных с профессиональной деятельностью, и оценки рисков для здоровья работников как необходимому элементу эффективного функционирования системы управления охраной труда на предприятии в свете современных требований к ней. Приведена оценка функиионального состояния организма работников строительного предприятия, разработаны рекомендации направленные на управление рисками в области охраны труда, предложены пути применения результатов исследования для управления рисками рабочей среды и трудового прочесса.

ключевые слова: функииональная система работников, риск, здоровье работников, предприятие, система управления охраной труда.

В соответствии со ст.201 Трудового Кодекса Республики Казахстан предприятия во время проведения внутреннего контроля должны включать в себя организацию создания и внедрения системы управления охраной труда, оценку рисков и принятие мер по ликвидации обнаруженных несоответствий с требованиями по безопасности и охране труда [1]. Изучение функционального состояния работников проводится с целью прогнозирования состояний, пограничных между здоровьем и болезнью в процессе профессиональной деятельности на рабочем месте. На данном этапе исследования переход от нормы к патологии рассматриваться как протекающий стадийный процесс адаптации организма к условиям рабочей среды, в ходе которого возникает качественно новое состояние работника - болезнь и состояние предболезни. Прогнозные экспериментальные модели состояний строятся на основе адаптационного потенциала 
(AП), который является важнейшим физиологическим показателем уровня приспособляемости организма человека к различным и меняющимся факторам внешней среды[2]. Исходя из вышеизложенного, исследования функционального состояния работников в зависимости от условий труда и степени профессионального риска является актуальным.

Для проведения исследования, на основании статьи 181 Кодекса РК от18.09.2009 г. № 193-IV «О здоровье народа и системе здравоохранения», с участниками исследований проведена процедура оформления письменного информированного согласия на участие в исследованиях. Далее у каждого работника измерялся рост и масса тела, регистрировался возраст, пол. Также для расчетно-экспериментального определения функционального состояния и физической работоспособности работников исследуемого предприятия проводили измерения систолического (САД) и диастолического (ДАД) артериального давления по методу Короткова и частоту сердечных сокращений в покое. После, у каждого работника рассчитывался адаптационный потенциал системы кровообращения по методу Баевского Р.М., в соавт. [3,4]: АП = 0,011× (ЧСС) + 0,014 × (САД) + 0,008 × (ДАД) $+0,014 \times(\mathrm{B})+0,009 \times(\mathrm{M})-0,009 \times(\mathrm{P})-0,273$, где, АП - адаптационный потенциал; ЧСС - чистота сердечных сокращений, уд/мин; В - возраст в годах; САД и ДАД систолическое и диастолическое артериальное давление, мм рт. ст.; ЧСС - частота сердечных сокращений, уд/мин; М - масса тела, кг; Р - рост испытуемого, см. В - возраст в годах. По значению АП определялась функциональное состояние работника. Далее, по шкале, функциональное состояние каждого работника были отнесены к определенной группе (Таблица 1).

Таблийа 1

Шкала определения функиионального состояния работников

\begin{tabular}{|l|c|}
\hline \multicolumn{1}{|c|}{ Пороговые значения функционального состояния } & баллы \\
\hline Удовлетворительная адаптация & Менее 2,60 \\
\hline Напряжение механизмов адаптации & $2,60-3,09$ \\
\hline Неудовлетворительная адаптация & $3,10-3,60$ \\
\hline Срыв адаптации & Более 3,60 \\
\hline
\end{tabular}

Оценка профессионального риска проведена на основе Методики расчета индивидуального показателя степени профессионального риска, которая разработана Институтом РГКП «РНИИОТ МТСЗН РК». Индивидуальный профессиональный риск рассчитывается на основе 5-ти показателей риска на рабочем месте для работника отдельно взятой профессии с учетом возможного воздействия факторов вредности условий труда, травмоопасности условий труда, безопасности производственного оборудования, обеспеченности средствами индивидуальной защиты и заболеваемости. С учетом последствий риски подразделяются на пять степеней: 1 степень - допустимый риск; 2 степень - низкий риск; 3 степень - средний риск; 4 степень - высокий риск; 5 степень - очень высокий риск. Оценка профессиональных рисков проведена по 64 должностям и профессиям производственного персонала.

При исследовании степени профессионального риска в разрезе по профессиям предприятии строительной отрасли было установлено: 2 степень риска у работников 7 профессии (17,19\%); 3 степень риска - 6 профессии (26,56\%); 4 степень риска 1 профессия (56,25\%). Профессиональный риск 3 и 4 степени был установлен для следующих 
профессий. 2 степень риска: - ИТР производство (Нач. участка, прораб, мастер, бригадир); 3 степень риска: ОТО производственный (Опалубщик, сварщик, стропальщик, электрик, плотник); 4 степень риска: Бригада (Арматурщик). Далее были получены результаты оценки профессиональных рисков по профессиям, по которым установлена 3 степень риска в разрезе 5-ти основных показателей риска подробнее. По результатам расчета оценки профессиональных рисков по 14 должностям и профессиям были установлены следующие степени риска: - 2 степень риска - 7 профессии (50\%); - 3 степень риска - 6 профессии (40\%); - 4 степень риска - 1 профессия (10\%); - 5 степень риска отсутсвует.

С целью выявления зависимости функционального состояния организма от условий труда и степени профессионального риска, была проведена оценка адаптационных возможностей работников. Общая численность участников обследования на предприятии строительной отрасли составила 53 работников из 7 различных профессий. Все участники были мужского пола в возрасте от 18 до 56 лет.

В таблице 2 представлены результаты оценки функционального состояния организма работников, с указанием профессий в 4-х группах функционального состояния работников, которые показаны в сравнительном анализе по 4 показателям профессионального риска.

Таблииа 2

Показатели адаптачионного потенциала, усредненные по профессиям и результаты оценки профессиональных рисков работников строительной отрасли

\begin{tabular}{|c|c|c|c|c|c|c|c|c|}
\hline \multirow[t]{2}{*}{$\begin{array}{c}\text { Наименование } \\
\text { профессии }\end{array}$} & \multicolumn{2}{|c|}{$\begin{array}{c}\text { Оценка } \\
\text { функционального } \\
\text { состояния } \\
\text { работников }\end{array}$} & \multirow[t]{2}{*}{$\begin{array}{c}\text { Степень } \\
\text { ПР }\end{array}$} & \multicolumn{5}{|c|}{ в том числе: } \\
\hline & Баллы & Группы & & 1 & 2 & 3 & 4 & 5 \\
\hline \multicolumn{9}{|c|}{1 группа (удовлетворительная адаптация до 2,6 балла) } \\
\hline Арматурщик & 2,52 & 1 & 4 & 3 & 5 & 2 & 4 & - \\
\hline Стропальщик & 2,50 & 1 & 3 & 2 & 4 & 2 & 3 & - \\
\hline Опалубщик & 2,42 & 1 & 3 & 2 & 3 & 2 & 4 & - \\
\hline \multicolumn{9}{|c|}{2 группа (напряжение механизмов адаптации от 2,6 до 3,09 балла) } \\
\hline Плотник & 2,63 & 2 & 3 & 2 & 5 & 2 & 4 & - \\
\hline Мастер & 2,71 & 2 & 2 & 2 & 3 & 2 & 2 & - \\
\hline Сварщик & 2,63 & 2 & 3 & 2 & 4 & 2 & 3 & - \\
\hline Электрик & 3,01 & 2 & 3 & 2 & 4 & 2 & 3 & - \\
\hline
\end{tabular}

1* - Оиенка вредности условий труда (вредности производственных факторов); 2 - Оиенка травмоопасности условий труда (опасности производственных факторов); 3 - Оченка безопасности производственного оборудования; 4 - Оиенка обеспеченности СИЗ; 5 - риск заболеваемости.

Так было установлено, что к удовлетворительной адаптации (1 группа) условиям труда относятся 3 профессии (40 \% от общего количества профессий). Напряжение механизмов адаптации было установлено у работников 4 профессий $(60 \%$ от общего количества профессий). У работников неудовлетворительная адаптация и срыв адаптации функционального состояния не выявлена. Сравнительный анализ оценки функционального состояния работников в возрастном аспекте с учетом стажа представлены в таблице 3. Все работники предприятия были разделены на 4 возрастных 
групп (1 группа-18-30 лет; 2 группа - 31-40 лет; 3 группа - 41-50 лет; 4 группа - 51-60 лет).

Таблица 3

Зависимость степени адаптации к условиям среды от возраста работников строительной отрасли

\begin{tabular}{|l|c|c|c|c|c|}
\hline \multirow{2}{*}{ Возрастные группы } & Число обследованных & \multicolumn{3}{|c|}{ Группы функционального состояния } \\
\cline { 3 - 6 } & & $\mathbf{1}$ & $\mathbf{2}$ & $\mathbf{3}$ & $\mathbf{4}$ \\
\hline 1-группа 18 - 30 лет & 29 & $72 \% / / 21$ чел. & $25 \% / / 7$ чел. & $3 \% / / 1$ чел. & - \\
\hline 2-группа $31-40$ лет & 16 & $43,5 \% / / 7$ чел. & $56,5 \% / / 9$ чел. & - & - \\
\hline 3- группа $41-50$ - & 4 & - & $100 \% / / 4$ чел. & - & - \\
\hline 4 - группа 51 - 60лет & 4 & $25 \% / / 1$ чел. & $50 \% / / 2$ чел. & $25 \% / / 1$ чел. & - \\
\hline \multicolumn{1}{|c|}{ ИТОГО } & 53 & $55 \% / / 29$ чел. & $42 \% / / 22$ чел. & $3 \% / / 2$ чел. & \\
\hline
\end{tabular}

* 1-удовлетворительная адаптация; 2- напряжения механизмов адаптации; 3неудовлетворительная адаптации; 4- срыв адаптации.

Результаты исследования показали, что у работников 1 и 4 возрастной группы (18$30)$ и (51-60) характерна удовлетворительная адаптация (72-25\%), напряжение механизмов адаптации $(25-50 \%)$ и неудовлетворительная адаптация $(3-25 \%)$. У работников 2 и 3 возрастной групп (31-40 и 41-50) установлены удовлетворительная адаптация $(43,5 \%)$ и напряжение механизмов адаптации (56,5 - 100). У работников данного предприятия срыв адаптации функционального состояния не выявлено.

Анализ зависимости функционального состояния от условий труда показал неудовлетворительную адаптацию у 29 летнего работника плотника (3,13 балла) со стажем работы всего 1 год. Такая реакция организма работника возможно связано на повышенную мышечную нагрузку (3.1), на травмоопасность производственной среды и трудового процесса, выявленных при проведений оценки профессионального риска. При этом, у другого работника этой же профессии в возрасте 51 год со стажем работы на данном предприятии 10 лет, функциональное состояние оценивается на 3,36 балла, это свидетельствует о том что, несмотря на разницу в возрасте реакция на условия производственной среды у данных работников одинаковы.

Следовательно, проведенные исследования функционального состояния работников строительной отрасли показали, что несмотря на разницу в возрасте адаптивная реакция функциональных систем в организме работников на условия производственной среды одинаковы, в связи с этим работникам строительной отрасли рекомендуется целенаправленные оздоровительные и профилактические мероприятия по повышению защитных свойств организма, усилению его компенсаторных возможностей.

\section{Выводы}

Оценка индивидуального риска у работников строительной отрасли оценивается как средний риск (3 степень), который требует проведения корректирующих мер по снижению риска в течение 6 месяцев после оценки риска. Но стоит отметить, что в подразделении бригады и производство ОТО у работника профессии арматурщика профессиональный риск оценен как высокий (4 степень), что требует проведения корректирующих мер в кратчайшие сроки. 
Оценка степени адаптации к условиям труда производства показали, что независимо от возраста адаптивная реакция функциональных систем в организме работников на условия производственной среды одинаковы, в связи с этим работникам строительной отрасли рекомендуется целенаправленные оздоровительные и профилактические мероприятия по повышению защитных свойств организма, усилению его компенсаторных возможностей.

\section{СПИСОК ЛИТЕРАТУРЫ}

1. Трудовой кодекс республики Казахстан (с изменениями и дополнениями по состоянию на 21.07.2018 г.).- С.133.

2. Есбенбетова Ж.Х., Бекеева С.А. Изучение взаимосвязи функционального состояния организма работников в машиностроительной отрасли с условиями труда. Сб.ст. Межд. конф. «Актуальные вопросы медицины труда в Казахстане «Хризотил и Здоровье» (Караганда, 1-2.11.2018 г.). - 2018. - С. 32.

3. Баевский Р.М., Берсенева А.П., Лучицкая Е.С. и др. Оценка уровня здоровья при исследовании практически здоровых людей. М.: Фирма «Слово», 2009. - 100 с.

4. http://cnit.ssau.ru/kadis/ocnov_set/tema3/text/3_2_4.html 